\title{
The VICl-trial: high frequency oscillation versus conventional mechanical ventilation in newborns with congenital diaphragmatic hernia: an international multicentre randomized controlled trial
}

Lieke van den Hout ${ }^{1}$, Dick Tibboel ${ }^{1}$, Sanne Vijfhuize ${ }^{1}$, Harma te Beest ${ }^{1}$, Wim Hop ${ }^{2}$ and Irwin Reiss $^{{ }^{*}}$, for The CDH-EURO Consortium

\begin{abstract}
Background: Congenital diaphragmatic hernia $(\mathrm{CDH})$ is a severe congenital anomaly of the diaphragm resulting in pulmonary hypoplasia and pulmonary hypertension. It is associated with a high risk of mortality and pulmonary morbidity. Previous retrospective studies have reported high frequency oscillatory ventilation (HFO) to reduce pulmonary morbidity in infants with $\mathrm{CDH}$, while others indicated HFO to be associated with worse outcome. We therefore aimed to develop a randomized controlled trial to compare initial ventilatory treatment with highfrequency oscillation and conventional ventilation in infants with $\mathrm{CDH}$.

Methods/design: This trial is designed as a multicentre trial in which 400 infants (200 in each arm) will be included. Primary outcome measures are BPD, described as oxygen dependency by day 28 according to the definition of Jobe and Bancalari, and/or mortality by day 28. All liveborn infants with CDH born at a gestational age of over 34 weeks and no other severe congenital anomalies are eligible for inclusion. Parental informed consent is asked antenatally and the allocated ventilation mode starts within two hours after birth. Laboratory samples of blood, urine and tracheal aspirate are taken at the first day of life, day 3, day 7, day 14 and day 28 to evaluate laboratory markers for ventilator-induced lung injury and pulmonary hypertension.

Discussion: To date, randomized clinical trials are lacking in the field of CDH. The VICI-trial, as the first randomized clinical trial in the field of $\mathrm{CDH}$, may provide further insight in ventilation strategies in $\mathrm{CDH}$ patient. This may hopefully prevent mortality and morbidity.

Trial registration: Netherlands Trial Register (NTR): NTR1310
\end{abstract}

\section{Background}

Congenital diaphragmatic hernia $(\mathrm{CDH})$ is a severe congenital anomaly of the diaphragm, which occurs in approximately one in 3000 live births [1]. In $\mathrm{CDH}$, the diaphragmatic defect allows abdominal organs to herniate into the chest cavity. As a consequence, underdevelopment of the lungs and abnormal pulmonary

\footnotetext{
* Correspondence: i.reiss@erasmusmc.nl

${ }^{1}$ Intensive care and Department of Pediatric Surgery, Erasmus MC - Sophia,

Dr. Molewaterplein 50, 3015 GE, Rotterdam, the Netherlands Full list of author information is available at the end of the article
}

vasculature growth may occur, resulting in pulmonary hypoplasia and pulmonary hypertension $[2,3]$.

Children with $\mathrm{CDH}$ mostly present with immediate cardiorespiratory distress during the first hours of life. The initial therapy for these children is mechanical ventilation and cardiorespiratory stabilization in support of optimal management of the pulmonary hypoplasia and pulmonary hypertension [4]. Thereafter, surgical repair of the diaphragmatic defect is indicated [4]. Although many advances in treatment for $\mathrm{CDH}$ patients have been made throughout the years, $\mathrm{CDH}$ remains a life-
C Biomed Central 
threatening condition with a reported mortality of 20 $70 \%$, depending on case selection [5].

Survivors of $\mathrm{CDH}$ are at risk of developing secondary morbidity, such as gastro-intestinal, neurodevelopmental and pulmonary sequelae. Throughout infancy and childhood, a broad spectrum of pulmonary morbidity may occur, such as bronchopulmonary dysplasia (BPD), persistent pulmonary hypertension, recurrent respiratory tract infections and asthmatic symptoms [6]. BPD is characterized by disturbances of the normal alveolarization. Ventilator-induced lung injury, oxygen toxicity, pulmonary inflammatory responses, and severe pulmonary hypertension predispose infants with $\mathrm{CDH}$ to develop BPD $[7,8]$. A recent report of the CDH Registry reported the prevalence of $\mathrm{BPD}$ to be $41 \%$ in infants with $\mathrm{CDH}$ [9]. About half of the $\mathrm{CDH}$ survivors with BPD are reported to have moderate to severe BPD [10]. Moreover, lung function anomalies are often present in these patients [11-14].

Optimizing ventilation strategies in patients with $\mathrm{CDH}$ may help to prevent chronic respiratory disease. However, evidence-based standardized treatment protocols based are lacking in the field of CDH. Consequently, ventilation strategies may differ between centres and ventilatory support is often based upon expert opinion [7]. To date, conventional ventilation is the most widely used initial ventilation mode in newborns with $\mathrm{CDH}$, while in many institutions high frequency oscillatory ventilation (HFO) is used as rescue therapy. In some centres, however, HFO is used as the initial ventilation mode.

HFO achieves adequate gas exchange by an oscillatory pump, which combines very high respiratory rates and low tidal volumes. HFO may improve gas exchange, promote uniform lung inflation, reduce barotrauma, and decrease the presence of inflammatory mediators [7,15-18]. HFO has been used in preterm infants with respiratory distress syndrome, either as an elective ventilation strategy or as a rescue therapy [16]. A Cochrane review, on the use of elective HFO compared to CMV in preterm infants, found a borderline significant reduction in the rate of chronic lung disease with the use of HFO [16]. A second Cochrane review described the use of HFO as a rescue therapy in term and near term infants with severe pulmonary dysfunction. Only one trial compared these two ventilation strategies prospectively, resulting in no significant difference in outcome, need for extracorporeal membrane oxygenation (ECMO), or complications [15,19].

In infants with $\mathrm{CDH}$, retrospective and observational studies reported improved survival and a lower incidence of chronic lung disease with elective use of HFO [20-25]. HFO was reported to provide better oxygenation and higher MAP without increasing the incidence of barotraumas $[20,21]$. In one study, the use of HFO avoided hyperventilation as well as the need for ECMO [17]. Moreover, inhaled nitric oxide was documented to result in better gas exchange following recruitment of the lungs by HFO [26]. On the contrary, HFO may cause lung hyperinflation in some patients, which may induce higher alveolar and mean airway pressures [21]. This may result in an increased risk of pulmonary barotrauma and hemodynamic instability [21]. A recent study by the CDH Registry reported HFO as initial ventilation mode to be associated with an increased rate of mortality and BPD [9]. In this study, it is speculated that infants who received initially HFO were more severely ill from the start [9].

Conclusively, chronic pulmonary morbidity and high mortality rates are major problems in infants with $\mathrm{CDH}$. Several retrospective and observational studies have reported that mechanical ventilation strategies may have an impact on outcome and pulmonary morbidity in $\mathrm{CDH}$ patients. Therefore, we aimed to develop a randomized controlled trial to compare initial ventilatory treatment with $\mathrm{HFO}$ and conventional ventilation in infants with $\mathrm{CDH}$. The acronym VICI is deducted from the words: HFO versus conventional Ventilation in Infants with Congenital diaphragmatic hernia: an International randomised clinical trial. In Latin vici means 'I have conquered' which refers to our patients with $\mathrm{CDH}$ which are very vulnerable and ill and sometimes have to struggle to survive.

The primary objective of this trial is to determine if there is a difference in the incidence of BPD and/or death within the first 28 days of life between newborns with congenital diaphragmatic hernia treated with high frequency oscillatory ventilation (HFO) and those treated with conventional mechanical ventilation (CMV) as initial ventilation mode. Secondarily, we also aim to compare the severity of BPD, ventilator-induced lung injury and pulmonary hypertension by using clinical and laboratory parameters.

\section{Methods/Design}

This study is designed as a prospective, randomized controlled multicentre trial. All participating centres are member of the CDH-EURO Consortium. This is a collaboration between European tertiary centres, who have an expertise in the field of $\mathrm{CDH}$. The CDH-EURO consortium was started in 2006 and aims at cooperation between centres, enhancement of research in the field of $\mathrm{CDH}$ and development of standardized evidence-based treatment protocols.

\section{Outcome measures}

The primary outcome measure is BPD and/or death within the first 28 days of life. Secondary outcome parameters are overall mortality, severity of BPD, number of 
days on the ventilator, number of treatment failures, ventilation-induced lung injury and pulmonary hypertension according to clinical and laboratory parameters and need for ECMO (only for ECMO centres). BPD is defined as oxygen dependency at day 28, according to the definition of Jobe and Bancalari [27]. The severity of BPD is also defined according to this definition (see table 1).

\section{Inclusion and exclusion criteria}

The study population consists of all infants antenatally diagnosed with $\mathrm{CDH}$ born at one of the participating centres.

Exclusion criteria are:

- Birth before a gestational age of 34 weeks

- Severe chromosomal anomalies, like trisomy 18 or trisomy 13, which may imply a decision to stop or not to start life-saving medical treatment

- Severe cardiac anomalies, expected to need corrective surgery in the first 60 days of life (such as transposition of the great arteries, truncus arteriosus or double outlet right ventricle)

- Renal anomalies associated with oligohydramnios

- Severe orthopaedic and skeletal deformities, which are likely to influence thoracic, and/or lung development (such as chest wall deformities and spine anomalies)

- Severe anomalies of the central nervous system

\section{Statistical analysis}

We estimated that a total of 400 newborns can be included within a period of three years. In a previous study of the $\mathrm{CDH}$ study group, the incidence of BPD and/or death within the first 28 days of life is reported to be about $50 \%$ [9]. Assuming a difference of $15 \%$ in BPD and/or death within the first 28 days between both treatment groups, 186 patients are required per arm for a power of $80 \%$ at two-sided alpha is 0.05 . To allow for some non-evaluable patients and dropouts, 200 patients per group will be included. To achieve equal distribution of the two ventilation modes among the participants, block randomization stratified per centre will be carried out. The data-analysis will be carried out at the Erasmus MC, Rotterdam. An intention-to-treat analysis will be performed. A p-value (two-sided) $<0.05$ will be considered significant in all analyses.

The primary endpoint will be evaluated using multiple logistic regression analysis taking account of: centre, lung-to-head ratio, position of the liver (intra-abdominal or intra-thoracic) and the side of the defect (left, right or central). A subgroup analysis will be carried out in operated infants to evaluate the defect size, according to the CDH study group defect size scale (http://www. cdhsg.net).

The secondary endpoints will be evaluated by using the following statistical tests. Overall mortality in the first year of life will be analysed by Kaplan-Meier curves and Log rank tests. The chi-square test will be used to analyse number of treatment failures, presence of pulmonary hypertension according to echocardiographic parameters, requirement of medication at discharge and during the first year of life, and need for ECMO therapy (in ECMO centres). The Mann-Whitney test is used to evaluate the severity of chronic lung disease, number of days on the ventilator and the fraction of days with required medical treatment for pulmonary hypertension during the hospital admission. In the evaluation of the severity of chronic lung disease and the number of days on the ventilator, deaths are counted as worst outcome according to the intention-to-treat principle. Repeated measures ANOVA is used to evaluate levels of laboratory markers for ventilator-induced lung injury or pulmonary hypertension and pulmonary function at the age of six and twelve months. This analysis allows for missing data at different time points and is considered as the optimal way for evaluation of longitudinal data.

All the above-mentioned analyses will allow for centre by stratification.

Table 1 definition of BPD according to Jobe and Bancalari

\begin{tabular}{|c|c|c|}
\hline Gestational age & $<32$ weeks & $>32$ weeks \\
\hline $\begin{array}{l}\text { Time point } \\
\text { assessment }\end{array}$ & 36 wks $\mathrm{PMA}^{*}$ or $\mathrm{DC}^{* *}$ to home, whichever comes first & $\begin{array}{l}>28 \text { days but }<56 \text { days of life or discharge to home, } \\
\text { whichever comes first }\end{array}$ \\
\hline \multicolumn{3}{|c|}{ Treatment with oxygen $>21 \%$ for at least 28 days PLUS } \\
\hline Mild BPD & On room air at 36 wks PMA or at DC, whichever comes first & $\begin{array}{l}\text { On room air at day } 56 \text { postnatal age or DC, whichever comes } \\
\text { first }\end{array}$ \\
\hline Moderate BPD & $<30 \% \mathrm{O} 2$ at 36 wks PMA or DC, whichever comes first & $<30 \%$ O2 at 56 d of life or DC whichever comes first \\
\hline Severe BPD & $\begin{array}{l}\geq 30 \% \mathrm{O} 2 \text { and/or pos. pressure at } 36 \text { wks PMA or DC } \\
\text { whichever comes first }\end{array}$ & $\begin{array}{l}\geq 30 \% \mathrm{O} 2 \text { and/or pos. pressure at } 56 \mathrm{~d} \text { of life or DC } \\
\text { whichever comes first }\end{array}$ \\
\hline
\end{tabular}

*PMA $=$ post-menstrual age

${ }^{* *} \mathrm{DC}=$ discharge 


\section{Study procedures}

Parental informed consent will be obtained antenatally to enhance quick randomization. Following antenatal diagnosis, the parents are to be counselled and will receive information about the study, including a patient information letter and an informed consent form. If both parents decide to participate in the study, as soon as possible after birth central randomization will take place by the treating physician using a website. This way concealed allocation is guaranteed. Within two hours after delivery, the allocated ventilatory treatment has to be started.

The patient receives the allocated ventilation treatment during the entire admission period on the intensive care unit. During surgery, the child preferably remains on the allocated ventilation type, provided the treating surgeon agrees. Should the surgeon opt for the other ventilation mode, the patient is switched to the allocated ventilation treatment again after surgery. If the patient has to be re-intubated within the first 60 days after the start of the allocated treatment, the patient receives the allocated treatment again. Patients are observed up to day 60 after birth or until discharge whichever comes first. In Figure 1, an overview of the study procedures is given.

\section{Standardized treatment and ventilation settings}

All infants participating in the VICI-trial are treated according to the same standardized treatment protocol which has been published recently [4]. This protocol of standard practice was decided upon available evidence and consensus between the participating centres.

After birth, all infants are immediately intubated. In general, our goals are to achieve preductal saturations between 85 and 95\%, postductal saturation levels above $70 \%$ and arterial $\mathrm{CO}_{2}$ levels between 45-60 mm Hg (permissive hypercapnia). Conventional mechanical ventilation is provided by a neonatal ventilator capable of positive pressure ventilation or triggered modes (Babylog ventilator, Dräger Medical, Germany). High frequency oscillatory ventilation (HFO) is provided by a high frequency oscillatory ventilator (Sensormedics 3100A/B HFO Ventilator, Viasys Healthcare, USA).

If the allocated treatment is conventional ventilation, the following settings are used: a peak inspiratory pressure (PIP) of 20-25 $\mathrm{cm} \mathrm{H}_{2} \mathrm{O}$, a positive end-expiratory pressure (PEEP) of 2-5 $\mathrm{cm} \mathrm{H}_{2} \mathrm{O}$ and a frequency of 40-60 per minute. In case of HFO, the settings are: a mean airway pressure (MAP) of 13 to $17 \mathrm{~cm} \mathrm{H}_{2} \mathrm{O}$, a frequency of $10 \mathrm{~Hz}$, an amplitude $\left(\Delta \mathrm{p}, \mathrm{cm} \mathrm{H} \mathrm{H}_{2} \mathrm{O}\right)$ of 30 to 50 obtaining chest vibrations, and an inspiration/expiration rate (I:E) of $1: 1$.

According to our standardized treatment protocol, a chest radiograph is made as soon as possible after birth to assess the initial condition and is repeated guided on the patient's condition. In case of HFOV, a chest radiograph is also made after this ventilation mode is started to confirm that the lungs are not overinflated, as defined by a contralateral lung expansion of over 8 ribs. Also, echocardiography is performed within the first 24 hours after birth to assess pulmonary arterial diameter and right heart function. In all patients, a chest radiograph and echocardiography are repeated at day 28 .

Weaning from conventional ventilation is done by means of decreasing PIP. Frequency and/or the PIPPEEP were modified to achieve $\mathrm{PaCO}_{2}$ levels above 45 $\mathrm{mmHg}$. In case of $\mathrm{HFOV}, \Delta \mathrm{p}$ was decreased if the $\mathrm{paCO}_{2}$ was below $45 \mathrm{mmHg}$ and $\mathrm{FiO}_{2}$ was decreased if preductal saturation levels were above $95 \%$.

In case of hypovolemia and/or cardiogenic shock, saline fluid therapy is started (10 to $20 \mathrm{ml} / \mathrm{kg}$ of $\mathrm{NaCl} 0.9 \%$ up to three times during the first one to two hours), which is followed by inotropic therapy if necessary. At an oxygenation index of 20 or higher and/or a pre- and postductal saturation difference of $10 \%$ or more, $10-20$ ppm iNO is given for at least one hour. Intravenous prostacyclin or prostaglandin E1 may be considered in case of no response to iNO. Sildenafil may be considered in the chronic phase of pulmonary hypertension.

Surgery is performed if the patient is physiologically stabile according to the criteria described in our protocol [4]. No routine paralysis is used.

\section{Treatment failure}

In case of one or more failure criteria, the allocated ventilatory treatment may be switched. Also, an ECMO procedure may be started in centres where ECMO is available. After the ECMO-procedure has ended, the patient preferably receives the initial allocated ventilation mode. Because an intention-to-treat analysis will be

\begin{tabular}{|c|c|c|c|c|c|c|c|c|}
\hline $\begin{array}{l}\text { Antenatal } \\
\text { counselling }\end{array}$ & $\begin{array}{l}\text { Birth and } \\
\text { randomisation }\end{array}$ & $\begin{array}{l}\text { Day } 1 \\
\text { Lab samples } \\
\text { Echo Cor } \\
\text { X-ray }\end{array}$ & $\begin{array}{l}\text { Day } 3 \\
\text { Lab samples }\end{array}$ & $\begin{array}{l}\text { Day } 7 \\
\text { Lab samples }\end{array}$ & $\begin{array}{l}\text { Day } 14 \\
\text { Lab samples }\end{array}$ & $\begin{array}{l}\text { Day } 28 \\
\text { Lab samples } \\
\text { Echo cor } \\
\text { X-ray }\end{array}$ & $\begin{array}{l}\text { Lung function } \\
6 \text { months }\end{array}$ & $\begin{array}{l}\text { Lung function } \\
12 \text { months }\end{array}$ \\
\hline
\end{tabular}


performed, data from these patients are stored and analysed the same way as data from patients in whom no switching of ventilation mode or ECMO procedure took place.

The following failure criteria are applicable to the study patients:

- Inability to maintain preductal saturations above $85 \%( \pm 7 \mathrm{kPa}$ or $52 \mathrm{mmHg})$ or postductal saturations above $70 \%( \pm 5.3 \mathrm{kPa}$ or $40 \mathrm{mmHg})$

- Increase in $\mathrm{CO}_{2}>65$ torr or $\mathrm{mmHg}(8.5 \mathrm{kPa})$ despite optimalization of ventilatory management

- $\mathrm{PIP}>28 \mathrm{~cm} \mathrm{H}_{2} \mathrm{O}$ or MAP $>17 \mathrm{~cm} \mathrm{H}_{2} \mathrm{O}$

- Inadequate oxygen delivery with metabolic acidosis defined as lactate $\geq 5 \mathrm{mmol} / \mathrm{l}$ and $\mathrm{pH}<7.20$

- Hypotension resistant to fluid therapy and adequate inotropic support, resulting in a urine output $<0.5 \mathrm{ml} / \mathrm{kg} /$ hour

- Oxygenation index consistently $\geq 40$

\section{Laboratory analyses}

During the study, blood, urine and tracheal samples are collected. Separate parental informed consent is asked for taking, analysing and storing these samples.

Blood, urine and tracheal samples are taken within the first 2 hours of life and on days 3, 7, 14 and 28. Blood sampling is only done if a central or peripheral line is present and in combination with routine laboratory measurements. Urine sampling is only done if the patient has a urine catheter. Sampling of tracheal aspirates is only done during routine suctioning. In that way, sampling of laboratory markers are of minimal burden for the patient.

\section{Blood samples}

Blood markers are determined by immuno-assay analysis and are necessary support evidence of chronic lung disease and to further evaluate its severity [28-32].

The following laboratory markers are measured:

- Markers for inflammation and pulmonary vascular endothelial dysfunction and pulmonary hypertension (intercellular adhesion molecule (ICAM), vascular cell adhesion molecule (VCAM), sP- and sE-selectine, pro-brain natriuretic peptide (Pro-BNP), vascular endothelial growth factor (VEGF), von Willebrand factor, thrombomodulin, factor VIII and Asymmetric Dimethylarginine (ADMA)

- Markers for the nitroxide pathway (nitrate and nitrite)

\section{Urine samples}

Two urine samples from an 8-hour urine collection are taken to measure desmosine, an elastolytic degradation product of elastin. It gives an indication of the degradation of lung elastic fibres in ventilated neonates. One sample of $20 \mathrm{ml}$ containing $0.2 \%$ boric acid and one sample of $10 \mathrm{ml}$ will be stored at -20 degrees Celsius. Desmosine will be measured by mass-spectrometry, a highly sensitive way of measuring this laboratory marker [33,34].

\section{Tracheal aspirate}

Protein profiling by proteomics are used for identifying specific groups of proteins, which are involved in the pathogenesis of chronic lung disease. During routine tracheal suctioning, flushing with $0.5-1.0 \mathrm{ml}$ saline is performed according to standard practice. The tracheal aspirates are centrifuged for 10 minutes at $3000 \mathrm{rpm}$ and are stored at -80 degrees Celsius $[35,36]$.

\section{Follow-up}

At all participating centres, routine follow-up takes place at the age of 6 months, 12 months, 24 months, 5 years, 8 years, 12 years and 18 years in all patients with $\mathrm{CDH}$, including participants of the VICI-trial. During followup visits, routine physical examination and additional testing (e.g. lung function tests or developmental tests) take place. For the purpose of this study, parents complete a patient diary card on a daily basis for one month at the age of six and twelve months. By using this diary card information about whether their child coughed, wheezed and/or needed medication is collected. This gives a quantitative assessment of morbidity.

In a subgroup of patients born at the Erasmus Medical Centre and King's College Hospital, lung function tests are performed at the age of six and twelve months. Only these two centres have the equipment and expertise to measure lung function in children below the age of one. At King's College, FRC (functional residual capacity) and LCI (lung clearance index) are measured by using helium gas dilution. The LCI is the cumulative expired volume required to clear an inert gas from the lungs, divided by the FRC. Also, lung function tests are performed before and after bronchodilation at this centre. Therefore, a bronchodilator is administered by a face mask and a spacer. At the Erasmus Medical Centre, the FRC is determined by plethysmographic measurements and the LCI is defined by SF6 measurements.

Since the methods of lung function measurements differ between the two centres, these measurements will be analysed separately for both centres.

\section{Safety reporting}

An adverse event or complication is defined as any undesirable occurrence in a patient. Mortality is regarded a serious adverse event. Adverse events or complications are reported to the study coordinator within 24 hours. Thereafter, the study coordinator informs the data safety monitoring board, who monitors 
the incidence of mortality on a continuous base. If at some point a large difference in mortality between the two treatment groups is noticed, the data safety monitoring board may recommend ending the study.

\section{Data collection}

Demographic and neonatal characteristics as well as data on the clinical course and treatment of all patients will be collected in a central database in Rotterdam. Corporeal material collected during the study is stored at the local centres.

Since it should be impossible to identify a specific patient, data are sealed by a code and a patient number replaces personal data. All centres keep a logbook of the number of eligible non-participants, including the reasons for not participating.

Patient data are stored during the study and for fifteen years after the study has ended. If the parents consent, corporeal material is also stored for fifteen years after the study has ended. This material may be used in future for a study with the same research aims.

\section{Ethical approval}

The first of October 2008, this study has been given approval by the medical ethics committee of the ErasmusMC Rotterdam. Thereafter, the local medical ethics committees of eleven participating centres gave their approval. In one centre, ethical approval is still being sought. Once a year, a summary of the trial's progress is send to the medical ethics committee of the ErasmusMC, Rotterdam, the Netherlands. Information is provided on the numbers of subjects included, (serious) adverse events, other problems and amendments. New participating centres are still included. We will continue recruiting patients for our trial until we reached the number of 400 participants. Our goal is to have this amount of patients included by the first of October 2013.

\section{Discussion}

Congenital diaphragmatic hernia $(\mathrm{CDH})$ is associated with a high risk pulmonary morbidity [6]. Several previous studies have reported a wide range of pulmonary problems throughout childhood in these patients [6]. A recent study of our group in collaboration with the CDH Registry reported a $41 \%$ prevalence of bronchopulmonary dysplasia (BPD) in survivors of $\mathrm{CDH}$ [9]. This study reported the initial ventilation mode to be possibly associated with BPD in these patients. This formed the rationale for our study, which aims at comparing HFO and conventional ventilation as initial ventilation modes in infants with $\mathrm{CDH}$.

Our study is the first randomized clinical trial in the field of $\mathrm{CDH}$. Previous studies were retrospective or observational reports, mostly from single centres.
Moreover, progress in $\mathrm{CDH}$ research is hampered due to small numbers of patients and lack of evidence-based treatment strategies. Cooperation between centres is therefore highly important to enhance research, exchange knowledge and compare data in larger groups of patients. The CDH Study Group is an example of a worldwide network which has established a large database on CDH patients. To date, the CDH Study Group has published numerous reports in the field of $\mathrm{CDH}$, which contain valuable information on survival, treatment strategies and morbidity in infants with $\mathrm{CDH}$. Another example is the CDH-EURO consortium, a European collaboration between tertiary centres with an expertise in treatment of $\mathrm{CDH}$, which also initiated the VICI-trial. The consortium also developed a recently published standardized treatment protocol [4]. This treatment protocol makes valuable comparison of patient data possible, since all $\mathrm{CDH}$ patients, including the VICI-trial patients, born in these centres are treated according to this protocol.

HFO and conventional ventilation are both safe, effective and widely used strategies to ventilate infants with respiratory distress. Although observational and retrospective studies have suggested that HFO may improve survival and pulmonary outcome in infants with $\mathrm{CDH}$, no prospective randomized controlled trials have been carried out to compare initial ventilation strategies in these patients. Therefore, no specific conclusions about certain benefits or disadvantages of either HFO or CMV can be made.

As the first randomized clinical trial in $\mathrm{CDH}$ infants, the VICI-trial will provide a clearer view on ventilatory treatment strategies and possible prevention of mortality and morbidity. Still, there are many questions left in the field of $\mathrm{CDH}$ and clinical trials are highly needed to improve care and establish standardized treatment. Cooperative networks between centres, such as the CDH-EURO consortium, play a major role in this.

\section{Acknowledgements \\ Following members of the $\mathrm{CDH}$-EURO Consortium are currently participating in the study, alphabetic order (local investigator): Bambino Gesù Hospital, Rome, Italy (I. Capolupo; P. Bagolan); Erasmus MC-Sophia, Rotterdam, the Netherlands (I. Reiss, D. Tibboel; R. Wijnen); Hospital Pediatrico de Coimbra, Coimbra, Portugal (J. C. Peixoto); Hospital d’ Estefania, Lisboa, Portugal (M. Serelha); Hospital Fernando Fonseca, Amadora, Portugal (R. Barroso);Hospital Garcia Orta, Almada, Portugal(M. Lopes Primo); Hospital San Joao, Porto, Portugal (M. Gorett Silva); Hospital de Santa Maria, Lisboa, Portugal (J. Sladanha);King's College, London, United Kingdom (A. Greenough); UMC Radboud, Nijmegen, the Netherlands (A. van Heijst); Universitätsklinikum Mannheim, Mannheim, Germany (T. Schaible; L. Wessel); \\ Universiteitsziekenhuis Gasthuisberg, Leuven, Belgium (K. Allegaert). \\ Financial disclosure \\ Solely departmental funding supported this study}

\section{Author details}

${ }^{1}$ Intensive care and Department of Pediatric Surgery, Erasmus MC - Sophia, Dr. Molewaterplein 50, 3015 GE, Rotterdam, the Netherlands. ${ }^{2}$ Department of 
biostatistics, ErasmusMC, Dr. Molewaterplein 50, 3015 GE, Rotterdam, the Netherlands.

\section{Authors' contributions}

Contributors: LH wrote the research proposal and the statistical analysis plan drafted and revised this paper, and currently monitors the data collection of this trial; DT initiated and supervises this trial, drafted and revised the paper, and currently monitors the data collection of this trial; SV currently monitors the data collection of this trial; $\mathrm{HB}$ assisted in setting up this trial and currently monitors the data collection of this trial; $\mathrm{WH}$ wrote the statistical analysis plan and revised the paper; IR initiated and supervises this trial, drafted and revised the paper, and currently monitors the data collection of this trial. All authors gave final approval of this manuscript to be published.

\section{Competing interests}

The authors declare that they have no competing interests.

Received: 24 March 2011 Accepted: 2 November 2011

Published: 2 November 2011

\section{References}

1. Ackerman KG, Pober BR: Congenital diaphragmatic hernia and pulmonary hypoplasia: new insights from developmental biology and genetics. Am J Med Genet C Semin Med Genet 2007, 145C:105.

2. Lally KP: Congenital diaphragmatic hernia. Curr Opin Pediatr 2002, 14:486.

3. Robinson PD, Fitzgerald DA: Congenital diaphragmatic hernia. Paediatr Respir Rev 2007, 8:323.

4. Reiss I, Schaible T, van den Hout L, Capolupo I, Allegaert K, van Heijst A Gorett Silva M, Greenough A, Tibboel D: Standardized Postnatal Management of Infants with Congenital Diaphragmatic Hernia in Europe: The CDH EURO Consortium Consensus. Neonatology 2010, 98:354.

5. Mah VK, Chiu P, Kim PC: Are We Making a Real Difference? Update on 'Hidden Mortality' in the Management of Congenital Diaphragmatic Hernia. Fetal Diagn Ther 2010.

6. Lally KP, Engle W: Postdischarge follow-up of infants with congenital diaphragmatic hernia. Pediatrics 2008, 121:627.

7. Logan JW, Cotten CM, Goldberg RN, Clark RH: Mechanical ventilation strategies in the management of congenital diaphragmatic hernia. Semin Pediatr Surg 2007, 16:115.

8. Mohseni-Bod H, Bohn D: Pulmonary hypertension in congenital diaphragmatic hernia. Semin Pediatr Surg 2007, 16:126.

9. van den Hout L, Reiss I, Felix JF, Hop WC, Lally PA, Lally KP, Tibboel D: Risk Factors for Chronic Lung Disease and Mortality in Newborns with Congenital Diaphragmatic Hernia. Neonatology 2010, 98:370.

10. van den Hout L, Schaible T, Cohen-Overbeek TE, Hop W, Siemer J, van de Ven K, Wessel L, Tibboel D, Reiss I: Actual outcome in infants with Congenital Diaphragmatic Hernia: the role of a standardized postnatal treatment protocol. Fetal Diagn Ther 2011, 29(1):55-63.

11. Hofhuis W, Hanekamp MN, ljsselstijn H, Nieuwhof EM, Hop WC, Tibboel D, de Jongste JC, Merkus PJ: Prospective longitudinal evaluation of lung function during the first year of life after extracorporeal membrane oxygenation. Pediatr Crit Care Med 2010.

12. Peetsold MG, Heij HA, Nagelkerke AF, ljsselstijn H, Tibboel D, Quanjer PH, Gemke RJ: Pulmonary function and exercise capacity in survivors of congenital diaphragmatic hernia. Eur Respir J 2009, 34:1140.

13. Gischler SJ, van der Cammen-van Zijp MH, Mazer P, Madern GC, Bax NM, de Jongste JC, van Dijk M, Tibboel D, ljsselstijn $\mathrm{H}$ : A prospective comparative evaluation of persistent respiratory morbidity in esophageal atresia and congenital diaphragmatic hernia survivors. J Pediatr Surg 2009, 44:1683.

14. Koumbourlis AC, Wung JT, Stolar CJ: Lung function in infants after repair of congenital diaphragmatic hernia. J Pediatr Surg 2006, 41:1716.

15. Bhuta T, Clark RH, Henderson-Smart DJ: Rescue high frequency oscillatory ventilation vs conventional ventilation for infants with severe pulmonary dysfunction born at or near term. Cochrane Database Syst Rev 2001, CD002974.

16. Henderson-Smart DJ, Cools F, Bhuta T, Offringa M: Elective high frequency oscillatory ventilation versus conventional ventilation for acute pulmonary dysfunction in preterm infants. Cochrane Database Syst Rev 2007, CD000104.

17. deLemos R, Yoder B, McCurnin D, Kinsella J, Clark R, Null D: The use of high-frequency oscillatory ventilation (HFOV) and extracorporeal membrane oxygenation (ECMO) in the management of the term/near term infant with respiratory failure. Early Hum Dev 1992, 29:299.

18. Sakurai Y, Azarow K, Cutz E, Messineo A, Pearl R, Bohn D: Pulmonary barotrauma in congenital diaphragmatic hernia: a clinicopathological correlation. J Pediatr Surg 1999, 34:1813.

19. Clark RH, Yoder BA, Sell MS: Prospective, randomized comparison of highfrequency oscillation and conventional ventilation in candidates for extracorporeal membrane oxygenation. J Pediatr 1994, 124:447.

20. Migliazza L, Bellan C, Alberti D, Auriemma A, Burgio G, Locatelli G, Colombo A: Retrospective study of 111 cases of congenital diaphragmatic hernia treated with early high-frequency oscillatory ventilation and presurgical stabilization. J Pediatr Surg 2007, 42:1526.

21. Ng GY, Derry C, Marston L, Choudhury M, Holmes K, Calvert SA: Reduction in ventilator-induced lung injury improves outcome in congenital diaphragmatic hernia? Pediatr Surg Int 2008, 24:145.

22. Somaschini M, Locatelli G, Salvoni L, Bellan C, Colombo A: Impact of new treatments for respiratory failure on outcome of infants with congenital diaphragmatic hernia. Eur J Pediatr 1999, 158:780.

23. Cacciari A, Ruggeri G, Mordenti M, Ceccarelli PL, Baccarini E, Pigna A, Gentili A: High-frequency oscillatory ventilation versus conventional mechanical ventilation in congenital diaphragmatic hernia. Eur J Pediatr Surg 2001, 11:3.

24. Miguet D, Claris O, Lapillonne A, Bakr A, Chappuis JP, Salle BL: Preoperative stabilization using high-frequency oscillatory ventilation in the management of congenital diaphragmatic hernia. Crit Care Med 1994, 22 : S77.

25. Reyes C, Chang LK, Waffarn F, Mir H, Warden MJ, Sills J: Delayed repair of congenital diaphragmatic hernia with early high-frequency oscillatory ventilation during preoperative stabilization. J Pediatr Surg 1998, 33:1010.

26. Kinsella JP, Truog WE, Walsh WF, Goldberg RN, Bancalari E, Mayock DE, Redding GJ, deLemos RA, Sardesai S, McCurnin DC, Moreland SG, Cutter GR, Abman SH: Randomized, multicentre trial of inhaled nitric oxide and high-frequency oscillatory ventilation in severe, persistent pulmonary hypertension of the newborn. J Pediatr 1997, 131:55.

27. Jobe $A H$, Bancalari E: Bronchopulmonary dysplasia. Am J Respir Crit Care Med 2001, 163:1723.

28. Walter RE, Wilk JB, Larson MG, Vasan RS, Keaney JF Jr, Lipinska I, O'Connor GT, Benjamin EJ: Systemic inflammation and COPD: the Framingham Heart Study. Chest 2008, 133:19.

29. Thebaud B: Angiogenesis in lung development, injury and repair: implications for chronic lung disease of prematurity. Neonatology 2007, 91:291.

30. Reynolds EW, Ellington JG, Vranicar M, Bada HS: Brain-type natriuretic peptide in the diagnosis and management of persistent pulmonary hypertension of the newborn. Pediatrics 2004, 114:1297.

31. Cella G, Saetta M, Baraldo S, Turato G, Papi A, Casoni G, Rigno M: Endothelial cell activity in chronic obstructive pulmonary disease without severe pulmonary hypertension. Clin Appl Thromb Hemost 2005, 11:435.

32. Cella G, Bellotto F, Tona F, Sbarai A, Mazzaro G, Motta G, Fareed J: Plasma markers of endothelial dysfunction in pulmonary hypertension. Chest 2001, 120:1226.

33. McClintock DE, Starcher B, Eisner MD, Thompson BT, Hayden DL, Church GD, Matthay MA: Higher urine desmosine levels are associated with mortality in patients with acute lung injury. Am J Physiol Lung Cell Mol Physiol 2006, 291:L566.

34. Ma S, Lin YY, Turino GM: Measurements of desmosine and isodesmosine by mass spectrometry in COPD. Chest 2007, 131:1363.

35. Magi B, Bargagli E, Bini L, Rottoli P: Proteome analysis of bronchoalveolar lavage in lung diseases. Proteomics 2006, 6:6354.

36. Bowler RP, Ellison MC, Reisdorph N: Proteomics in pulmonary medicine. Chest 2006, 130:567.

\section{Pre-publication history}

The pre-publication history for this paper can be accessed here: http://www.biomedcentral.com/1471-2431/11/98/prepub

doi:10.1186/1471-2431-11-98

Cite this article as: van den Hout et al:: The VICl-trial: high frequency oscillation versus conventional mechanical ventilation in newborns with congenital diaphragmatic hernia: an international multicentre randomized controlled trial. BMC Pediatrics 2011 11:98. 